\title{
Pedagogia da infância no Brasil e NA ITÁlIA: A CRIANÇA EM CONTEXTOS INTERCULTURAIS MARCADOS HISTORICAMENTE PELO RACISMO ${ }^{1}$
}

\author{
Childhood PEDAGogy In BRAZIL ANd ItAly: THE CHILD IN \\ INTERCULTURAL CONTEXTS HISTORICALLY MARKED BY RACISM
}

\author{
Flávio Santiago \\ Doutorado em Educação pela Universidade Estadual de Campinas. Pesquisa- \\ dor no Grupo de Pesquisa GEPEDISC - Linha Culturas Infantis. \\ ORCID: https://orcid.org/0000-0001-7019-2042 \\ flavio.fravinho@gmail.com
}

Márcia Lúcia Anacleto de Souza

Doutorado em Educação pela Universidade Estadual de Campinas. Pesquisadora no Grupo de Pesquisa GEPEDISC - Linha Culturas Infantis.

Professora de educação infantil na Prefeitura de Campinas -SP

ORCID: https://orcid.org/0000-0002-9652-8410 negramarsea@gmail.com

\begin{abstract}
Ana Lúcia Goulart de Faria Doutora em Educaçáo pela Universidade de São Paulo. Professora da Universidade Estadual de Campinas. Coordenadora do Grupo de Pesquisa GEPEDISC - Linha Culturas Infantis. ORCID: https://orcid.org/0000-0002-1886-3790 cripeq@unicamp.br
\end{abstract}

Resumo: Este artigo busca, a partir dos estudos pós-coloniais, da sociologia das relaçóes raciais e de dados de pesquisas bibliográficas acerca das culturas infantis, problematizar a educação das crianças pequenas em contextos históricos e sociais marcados por processos de racialização. Trata-se de inquietaçôes que emergem de pesquisas realizadas em um contexto transnacional Brasil-Itália, preocupadas em compreender o lugar das crianças no debate a respeito de cidadania e direitos, tendo em vista realidades marcadas pela imigração e por históricas relaçôes étnico-raciais que resultam em fenômenos sociais, culturais e políticos pautados na segmentação e segregaçáo social e racial. No contexto italiano, analisa-se a Educação Infantil e os desafios que o movimento migratório das últimas décadas coloca para as creches e pré-escolas, em termos interculturais. No Brasil, retoma-se a trajetória histórica de construção de uma pauta político-educacional que envolva a diversidade cultural e étnico-racial, frente à monoculturalidade, encaminhando perspectivas no campo da interculturalidade. Com base nas análises, pode-se destacar que os efeitos do racismo são semelhantes entre os dois países, pois correspondem a uma forma de estruturação da sociedade, mas com características distintas em sua forma de segregaçáo e hierarquização, colocando um desafio à construção de práticas pedagógicas para a infância nos dois países. Palavras-chave: Crianças Pequenininhas; Infâncias; Interculturalidade; Pedagogia da Infância; Racismo. 
AвSTRACT: This article aims, from the postcolonial studies, the sociology of race relations, and bibliographic research data on peer cultures, to problematize young children's education in historical and social contexts marked by processes of racialization. It is about disquietudes that arise from the research carried out in a Brazil-Italy transnational context, concerned with understanding the children's place in the debate of citizenship and rights, considering the realities marked by immigration and historical ethnic-racial relations that result in social, cultural, and political phenomena that are built upon social and racial segmentation and segregation. In the Italian context, the article analyzes child education and the challenges that the migratory movement in the last decades have posed to daycare centers and preschools in intercultural terms. In Brazil, the historical trajectory of the construction of a political educational agenda that involves the cultural and ethnic-racial diversity is resumed against the monoculturality, guiding perspectives in the field of interculturality. Based on the analyses, it can be emphasized that the effects of racism are similar between the two countries since they correspond to a form of structuring of the society, but with distinct characteristics in their form of segregation and hierarchization, posing a challenge to the construction of educational practices for children in both countries.

KeYwords: Young Children; Childhoods; Interculturality; Childhood Pedagogy; Racism.

Este artigo busca, a partir dos estudos pós-coloniais e da sociologia das relaçóes raciais, problematizar a educação das crianças pequenas em contextos históricos e culturais marcados pelo racismo, tendo em vista as inquietaçóes resultantes de pesquisas desenvolvidas em um contexto transnacional Brasil-Itália.

Ao longo da história, as diferenças raciais têm sido utilizadas como justificativas para a hierarquização social e "historicamente, isso significou uma nova maneira de legitimar as já antigas ideias e práticas de relaçóes de superioridade/inferioridade entre dominantes e dominados." (QUIJANO, 2005, p.118) Essa realidade também reverbera nas pedagogias construídas em creches e pré-escolas, como explicitam as pesquisas já realizadas no campo que propõe o debate educação e relaçóes raciais, e também nas pesquisas de campo que temos desenvolvido nos últimos anos. (CAVALLEIRO, 2003; DIAS, 1997, 2007; OLIVEIRA, 2004; PEREIRA, 2019; ROSEMBERG, 1996; SOUZA, 2012a; SANTIAGO, 2014, 2019; TRINIDAD, 2011)

Instigados pelas realidades analisadas, levantamos as seguintes questóes: Por que o cuidado e o afeto são diferenciados em relação a crianças negras e não negras? O que os/as bebês não negros/as têm de tão 'repulsivo'? Por que os/as bebês negros/as se tornam invisíveis ao acolhimento e ao afeto na creche? 
Para responder a esses questionamentos, primeiramente, abordamos os processos de segmentação e hierarquização que sustentam as desigualdades raciais nas sociedades italianas e brasileiras. Em sequência, tratamos de problematizar como esse processo se relaciona com a educação das crianças pequenininhas ${ }^{2}$ na Educação Infantil.

\section{Infâncias, Cidadania e Direitos Frente aos Processos de Racializaçáo: Brasil e Itália}

No Brasil, como já apontaram os sociólogos Bastide e Fernandes (2008, p. 95), o fenótipo negro tornou-se um signo social de identificação da pobreza e da exclusáo, passando a se constituir como um "ponto de referência imediatamente visível e inelutável, por meio do qual se poderia presumir a situação de um indivíduo isolado, como socius e como pessoa, tanto quanto definir o destino de uma raça.”

O racismo, no Brasil, está ligado à estrutura de classe, que o naturaliza, sendo necessário o entendimento das formaçóes históricas da sociedade para a compreensão dos mecanismos de hierarquização social. Como destaca Fernandes (2007, p. 289):

[...] seria lamentável se ignorássemos como as determinaçóes de raças se inseriram e afetaram as determinaçóes de classe [...] o que desapareceu historicamente - o mundo colonial - subsiste institucional e funcionalmente, ainda que de forma variável e desigual, conforme os níveis de desorganização da vida humana que se considerem. Ele vive, pois, em quase tudo que é essencial para o capitalismo dependente: na posse da terra, na organização da agricultura, na autocracia dos poderes, na espoliação sistemática e marginalização dos pobres, no particularismo e no farisaísmo das elites, na apatia ou na confusão das massas oprimidas e, principalmente, nos padrōes de relação étnicas e raciais.

A partir de uma abordagem histórico-sociológica, o referido sociólogo analisa os dilemas da inserção dos negros na ordem capitalista e 
competitiva, propondo que a situação de anomia social dos negros se deve ao arcaísmo de estruturas sociais herdadas do processo de escravização. Fernandes (2008) demonstra que a mudança do estatuto de escravo para homem livre, no pós-abolição, não foi acompanhada por uma efetiva integração do negro na sociedade de classes em formação. Identificam-se, nesse período posterior, a continuidade e a persistência de relaçóes sociais fundadas no período escravista na sociedade de classes.

Já no debate a respeito do processo de racialização no contexto italiano, que se espalham em grande parte da Europa, os trabalhos partem do conceito de interculturalidade para compreender esse fenômeno, contudo como destacam Curcio e Mellino (2012), esse processo tem sido construído com base na subjetividade e na cultura, de modo a emergir um projeto educativo que visa à unificação do tecido social e à relativização da ideia multicultural/intercultural enquanto princípio antirracista, se esquecendo da estrutura social que o construí.

Esse mecanismo não é um mero 'preconceito'. Sua 'força' depende, sobretudo, das hierarquias, do sistema de privilégios e da violência material da qual é veículo, não configurando simplesmente como um estereótipo. As sociedades racistas se formam precisamente a partir da proliferação de espaços e nichos altamente hierarquizados e racializados que de alguma forma transcendem a vontade e a subjetividade de indivíduos e grupos. (CURCIO; MELLINO, 2012)

Nesse modo de pensar o processo de racialização, visto somente a partir da perspectiva de relativização da ideia multicultural/intercultural, revela-se o lado eurocêntrico e colonial ainda presente no pensamento italiano, apontando o racismo táo somente como um elemento secundário e relativamente simples, sendo em muitos momentos pensado apenas como um elemento politicamente contingente e não estrutural das sociedades modernas. Como apontou Miguel Melino, professor na da Università degli studi di Napoli L'Orientale, em entrevista concedida a Santiago (2018, p. $573-574)$ :

$\mathrm{Na}$ América Latina, por ser uma realidade mais permeada pelo conflito que o dispositivo colonial trouxe para a sociedade, existe uma reflexão sobre a questão racial, o racismo, que é muito diferente daquela que existe na Europa. Infelizmente, 
na Europa, excluindo a Inglaterra, o que prevalece é uma visão do racismo muito plasmada, ou como apêndice de um certo tipo de marxismo que eu chamei, num texto meu, de marxismo branco. [...] Fala-se mais de classe, fala-se mais de bom grado sobre outras coisas; mas de raça e racismo, como problema e como algo que está dentro da cultura da sociedade europeia, fala-se menos.

Então, sim, posso dizer que há uma diferença a respeito da forma com que o racismo é visto na América Latina e, também, veja, a Europa tem um problema específico com o passado colonial, no sentido de que, antes de os migrantes chegarem em massa aqui na Europa não era claríssimo para os europeus o quanto sua identidade cultural, e mesmo a produçáo das sociedades europeias como população, eram construídas também a partir do dispositivo racial.

A dimensão material e estruturante do racismo coloca-o no centro da mesma constituição colonial da modernidade capitalista e no centro da construção e narração dos Estados nacionais modernos e, portanto, nos termos de seus próprios conceitos de cidadania, bem como de construção da percepção do que seja a infância e de quem tem direito a 'vivenciá-la'. Nesse contexto, o conceito de interculturalidade, que tem sido a chave teórica para compreender a existência de uma dinâmica multicultural dentro do país, também se limita a pensar as estruturas sociais e as experiências de integração social que cada criança imigrante vive no contexto italiano.

Para compreender o atual cenário intercultural da Itália, é fundamental lembrarmos, como aponta Silva (2011), que há uma pluralidade de vivências migratórias. Contemporaneamente, grande parte das crianças imigrantes nasceu em território italiano, tendo a experiência de imigração apenas os seus genitores; outras são natas em seus países de origem familiar, mas passam a viver na Itália por meio da reunificação familiar. Paralelamente a essas experiências de imigração, há os filhos e as filhas de casais mistos, as crianças que são adotadas e os filhos e filhas de pessoas que requereram asilo por refúgio político ou de guerra. A variedade de situaçôes que levam as crianças a imigrarem constitui um mosaico, formado 
por diversas histórias marcadas por vivências racialmente diferenciadas e normatizaçóes plurais das relaçóes de gênero.

Nesse sentido, pensar a Pedagogia da Infância é evidenciar, no contexto da dinâmica educativa, não uma genérica e abstrata infância, mas sim crianças reais, as quais são marcadas pelas condições de vida que forjam experiências de infâncias diferenciadas. $\mathrm{O}$ respeito para com as crianças implica o descentramento do olhar dos adultos de modo a procurar compreendê-las por meio de suas experiências e considerando suas realidades, para desse modo construir dinâmicas educativas que sejam relevantes ao contexto em que se constrói a Pedagogia da Infância. Isso exige disposição dos/as adultos/as a adaptar-se, mover-se, tornar-se um sujeito aberto, mas de modo a não limitar a sua atividade profissional (INFANTINO, 2018). O respeito não pode ser somente uma declaração de princípios, mas implica empenho e disposição para pensar o que está envolvido no interior das relaçôes com as crianças, construindo significados que possuam valores reconhecíveis e de reconhecimento, os quais também não são estabelecidos de modo automático com a presença de móveis na altura das crianças, ou com dois ou três livros de literatura infantil que versem a respeito da interculturalidade presente na creche. $\mathrm{O}$ projeto educativo da creche deve ser pensado e construído de modo a introduzir permanentemente subsídios materiais que buscam pensar a condição infantil, bem como a diversidade cultural, sendo um fundamento da prática pedagógica e não momentos eventuais que expressam a tentativa de solução de alguns problemas, pois "é necessário resistir à tentação de simplificar o contexto." (TOGNETTI, 2016, p. 283)

Em entrevista concedida a Santiago (informação verbal, 2018), Clara Silva, professora da Università degli Studi di Firenze, destacou que:

A intercultura é um tema que se desenvolveu na Itália desde o início dos anos 1990. Iniciou-se no começo dos anos 1990, quando começam a chegar, de modo maciço, às escolas os filhos da imigração, que eu chamo de filhos da imigraçáo, não só de filhos dos imigrantes, isto é, aquelas crianças que têm, por trás, uma família com história de imigração. As crianças não são imigrantes, porque nasceram aqui - sim, há, também, os imigrantes com os seus pais, ou os que chegaram por reagrupa- 
mentos familiares - porém cresce cada vez mais o número de crianças nascidas aqui que não são imigrantes, mas têm, por trás, uma história de imigração. A chegada dessas crianças às escolas, primeiro à escola primaria obrigatória e, depois, as creches, de modo particular para aquelas que nasceram na Itália, levantou este tema da intercultura, que já tinha se mostrado um pouco nos países europeus que enfrentaram antes o tema das imigrações recentes É um tema importante. Tem um ponto de vista - este tema da intercultura e da pedagogia intercultural - que é um tema interessante, é uma atenção pedagógica interessante, porque aborda o tema da diversidade, do pluralismo, da especificidade dos sujeitos, do diálogo. E, além disso, relaciona-se, também, à história dos povos, das culturas. Veemse os entrelaçamentos, veem-se, também, os nós problemáticos. Portanto, é importante este tema como tema de estudo e de pesquisa. Porém, é necessário prestar muita atenção, porque, se, por um lado, é interessante por esse ângulo, por outro lado, contudo, pode ser, também, um modo para criar maior divisão, maior separação onde não existe. E, de modo específico, se falarmos em relação às crianças pequenas, que estão formando a sua identidade. Por isso, a intercultura é, na verdade, uma faca de dois gumes. E, então, é muito importante a atenção do pesquisador, ter clareza em nível terminológico, em nível de conceitos, em nível de léxico. Eu, por exemplo, nos meus estudos e pesquisas, embora não se veja à primeira vista, estou muito atenta à expressão que uso, mesmo sabendo que se trata de conceitos difíceis, que não têm uma explicação unívoca, porque uma coisa é dizer "extracomunitários" em sentido genérico, outra coisa é falar dos filhos da imigração, em que se ressaltam a dimensão biográfica e a experiência de ser migrante. Para mim, há uma grande diferença. É, portanto, muito importante, exatamente em nível do conceito.

A pesquisadora Silva (2018), durante a entrevista, também destacou a importância de se pensar a interculturalidade dentro da sociedade que recebe as crianças estrangeiras: 
Eu penso, porém, que a intercultura sirva, sobretudo, à sociedade que acolhe, antes de tudo, que deve ter clareza quanto ao modo pelo qual quer se relacionar com esses recém-chegados, falando, precisamente, das sociedades da imigração. Além disso, uma coisa é o Brasil, outra coisa é Cabo Verde. Eu sou originária do arquipélago de Cabo Verde, e falar de intercultura em relação a Cabo Verde, imagino que seja algo semelhante ao Brasil. Há alguma semelhança, embora cada país tenha se desenvolvido de maneira diferente, e isso deve ser tido como referência de base. Falar de intercultura, quanto aos países da imigração, significa estar muito atento para pensar em como esse debate e essa reflexão sejam funcionais, em primeiro lugar, para a sociedade de chegada. Obviamente, melhorar a predisposição da sociedade de chegada ao acolhimento traz uma vantagem para quem chega. Isso é um ponto. Depois, há outro ponto ligado ao respeito à especificidade de quem chega; porém esse respeito não pode existir se náo houver uma predisposição ao acolhimento. Portanto, é por isso que digo que, antes de tudo, é funcional criar uma atitude de escuta, de acolhimento e de reflexão, uma atitude em que colocar em discussão estereótipos e preconceitos. Assim, toda a história dos povos são histórias mestiças. Eu a vejo desse ponto de vista, embora de maneira diversa. Portanto, uma coisa é a mestiçagem em Cabo Verde, onde os europeus foram e pegaram homens e mulheres como escravos na África e os levaram, e daí nasceu essa mestiçagem. Uma mestiçagem, também forçada, que também tem, em suas bases, mecanismos de violência. Uma coisa é isso. Além disso, de qualquer forma, a Itália também foi um país em que, até a constituição da unidade italiana, os povos e as culturas se encontraram pelas conquistas. Então, essa história, que é a história dos povos, das culturas, são sempre histórias de mestiçagem. E devemos dizer isso como premissa. Temos de dizer isso como premissa, sobretudo, temos de lembrar desses aspectos sempre, embora hoje seja muito difícil, porque parece que temos de trabalhar no "aqui e agora". Portanto, os educadores que trabalham nas creches querem receitas e parece que 
esse passado não seja tão importante. Na verdade, é importante porque permanece dentro, e, para mim, relembrar sempre esse passado quer dizer, também para a sociedade que acolhe, tomar consciência da própria identidade, não da própria identidade mestiça, do fato que, além disso, as culturas se transformam. E, assim, de também ter menos medo em relação aos novos que chegam e ver, também, a hibridização como uma condição humana, uma condição da história humana.

Para a construção dessa forma de pensamento, é fundamental estarmos atentos aos pormenores: ao toque, no momento da troca de fralda; ao acolhimento pelo olhar; à disponibilidade de ouvir o que as crianças nos dizem, não somente com ouvidos atentos, mas com o corpo todo. A creche que respeita os direitos das crianças é acolhedora e para isso devemos ser sensíveis no olhar para com as crianças, pois, caso isso não ocorra, faltarão informaçôes para conhecê-las. Desse modo, torna se fundamental observarmos concretamente, não no sentido de uma técnica, mas como orientação mental imbricada numa postura profissional. Esse movimento também não se limita ao presente, deve levar em consideração que existe um passado que constrói um futuro : "a observaçáo aprofundada deve ser considerada um trabalho que faz parte dos deveres das educadoras." (FONTAINE, 2017, p. 35)

Todavia, é fundamental destacar que aquilo que observamos está ligado à postura que adotamos, às bases teóricas que constroem o nosso olhar para com as crianças pequenininhas, ou seja, as lentes das observações são construídas pela nossa formação, por aquilo que lemos, nossos posicionamos políticos e nossas vivências ao longo de nossa trajetória profissional. A observação, como método, implica uma atitude educativa baseada na capacidade de pensar e refletir, fundamentada na escuta e na compreensão profunda daquilo que está acontecendo no contextoDurante a observação, um ponto central é partir da premissa de que todas as crianças têm o direito a serem lembradas, para compreendermos as suas subjetividades e singularidades; só a partir desse movimento podemos perceber quais são seus interesses e desejos. Os aspectos que consideramos importantes durante a observação têm a ver com o que colocamos em foco. $\mathrm{Na}$ Educação Infantil não deve mirar exclusivamente o indivíduo, mas levar 
à compreensão da dinâmica do coletivo infantil, de modo a proporcionar uma reflexão constante do que estamos propondo às crianças e de como organizamos o espaço - observar e problematizar o fazer cotidiano possibilita o aprofundamento do trabalho educativo. O que observamos não é neutro, indicam nossas escolhas profissionais, o quadro teórico que recorta nossas práticas pedagógicas.

O reconhecimento do impacto das experiências a respeito do nosso modo de observar o mundo e, nesse contexto, o modo de observar as crianças pequenininhas na creche, contribui para pensar a localização social do sujeito que realiza a observação. Como destaca Jedlowski (2008), não falamos a partir de um vazio, por mais oculto que seja; o pano de fundo do que cada um tem vivido também atua na construção de nossas interpretaçóes acerca das relaçóes sociais e estrutura as formas com as quais formulamos as nossas perguntas e como procuramos respondê-las ou não.

Nesse sentido, Paola, estudante do curso de Ciência da Formação, destaca que:

Estou convencida de que as crianças sempre participam da sociedade, isto é, mesmo que elas não nos digam o que veem, isso não significa que elas não experimentam o que observam. Uma vez que eu estava na estação com meu sobrinho ( 5 anos de idade), eu tinha que fazer a recarga mensal do meu bilhete urbano e ele queria vir comigo para ver os trens, porque ele gosta muito deles. Eu estava sentado no banco e ele estava esperando na minha frente que o trem passasse, mas a certa altura um senhor passa, acho que ele era paquistanês, ele olhou para o meu sobrinho e sorriu. Mas meu sobrinho permaneceu imóvel para observá-lo e quando o senhor estava longe, com o rosto irritado, meu sobrinho disse "ele é ruim"; fiquei muito perplexa e, na verdade, perguntei "por que ele está ruim?" mas não obtive respostas, porque o trem chegou. Eu imediatamente me perguntei se ele ouviu de alguém, pois eu não acredito que ele pensa assim, é o resultado de uma série de observaçóes que ele fez em várias circunstâncias, na rua, olhando para a tv, ouvindo as pessoas. 
Quando nos atentamos para diferenças culturais, constatamos a necessidade de encontrar ferramentas que possibilitem compreender a dinâmica da vida, o nosso local dentro da sociedade, bem como problematizar a nossa relação com o 'outro', que inúmeras vezes é construída com base no oposto do que seja o branco, europeu, homem cisgênero e adulto. No entanto, como aponta Nigris (2015), nos últimos vinte anos, no contexto europeu, observamos uma resistência a pensar a pluralidade de culturas, ocasionando um movimento que oscila entre soluçóes universalistas e homogeneizadoras; tenta-se tornar a diversidade invisível e entre linhas de pensamentos de natureza interculturais que em diversos momentos colocam a atenção para as diferenças culturais, mas que reproduzem uma imagem cultural estereotipada do outro.

Os estudos relativos à Pedagogia Intercultural (CESAREO, 2000; VIGNA, ZAMAGNI, 2004; HANNERZ, 2001, SILVA, 2011) procuram pensar processos de não homogeneização, desarticulando estereótipos e procurando uma interlocução entre as diferentes culturas. No entanto, mesmo nesse contexto, observa-se uma tendência à concentração de busca de interlocução com determinados tipos específicos de experiências, as quais, em sua maioria, correspondem às culturas do continente europeu (NIGRIS, 2015). Essa escolha política não faz mais do que revelar o lado eurocêntrico e colonial do próprio processo de construção da estrutura de pensamento da pedagogia intercultural italiana, tomando as questôes raciais como efeitos secundários e relativos, como um elemento politicamente contingente e não estruturante. Por isso, um caminho é reler criticamente o modelo político e o modelo educacional herdado da modernidade, para entender em que valores se fundamenta o modelo de cidadania e de educação posto na Itália contemporaneamente. É hora de avaliar, por exemplo, se a educaçáo pode continuar a ser concebida como um instrumento para fortalecer o poder das classes dominantes e a cultura eurocêntrica, como tem acontecido com muita frequência, ou se deveria ser relacionada dialeticamente com a política, ensinando a todos a serem autônomos e críticos, mas também cooperativos. (SIRNA, 2003)

Esses contextos estão conectados à própria percepção moderna de cidadania e cultura. Para Clara Silva (infomação verbal, 2018): 
O tema das diversidades não é muito bem enfocado, porque, para focalizá-lo, primeiramente, é necessário entender - esse é o meu ponto de vista - como a Itália vê essas crianças das migraçóes, qual espaço é dedicado a elas. $\mathrm{Na}$ verdade, a situação é um pouco confusa; basta pensar que temos uma lei referente à cidadania que ainda segue o modelo do início do século XX, quando a lei sobre cidadania devia proteger os italianos que iam embora e que migravam. Já faz muitos anos que estamos solicitando uma nova lei referente à cidadania. Houve, no início dos anos 1990, uma lei, que, porém, retoma aquela. Entretanto, solicitamos uma nova lei, que também leva em consideração as crianças nascidas aqui e que encurta o tempo de espera para que as crianças nascidas aqui ou que chegaram pequenas tenham a cidadania italiana.

E, praticamente, é difícil fazer com que a lei vá adiante; após um debate muito longo, conseguimos fazer com que essa lei fosse adiante, essa solicitação de lei sobre a cidadania à Câmara, em outra legislatura. Depois, a lei ficou parada no Senado e não foi possível aprová-la no final da legislatura. Agora, estamos sem governo, porém foram apresentadas muitas leis, entre as quais, também o decreto 65 e a lei Iori, sobre os educadores, que foram apresentadas e foram adiante. Entretanto, a lei sobre a cidadania não foi adiante. Esse fato de que não se consegue promulgar uma nova lei sobre a cidadania explica a rigidez cultural da Itália no tocante ao acolhimento total dos filhos da imigração, explica a falta de clareza cultural quanto ao que significa a presença dessas novas crianças.

E, portanto, basta dizer isso para entender que, sobre a intercultura, no tocante à diversidade, ainda estamos longe de ter uma clareza para poder dizer "está bem, enfrentemos o tema da diversidade", porque, em minha opiniáo, para contar realmente o tema da diversidade, ou seja, o reconhecimento das especificidades de cada um, temos de construir uma base comum.

Somos todos cidadãos, somos italianos diversos, e, assim, essa especificidade, essa outra especificidade e essa outra... 
Enquanto náo houver clareza quanto ao que nos tornamos com a imigração, não acredito que seja realmente possível ir falando.

A questão da cidadania, imposta pelos diversos fluxos migratórios na Itália, tem colocado em xeque o conceito moderno de Estado, destacando tanto o multiculturalismo quanto o transculturalismo, de modo a caracterizar o tecido social para além da percepçáo homogênea criada dentro dos limites do conceito de nação, tema esse colocado em questão por Mellino (2005). Um outro aspecto também fundamental para o processo de construção de uma educação intercultural, como avaliam Caronia e Bolognesi (2015), é o questionamento constante do ponto de vista a partir do qual designamos ou categorizamos os indivíduos.

Nas observaçóes de Faria (2003), as redes públicas municipais da Itália, desde o final dos anos de 1960, vêm aprimorando sua política e pedagogia para as crianças pequenas. Ao fazermos referências a elas, não estamos querendo copiá-las - afinal, nós brasileiros/as temos muito que contribuir com inquietaçóes aos italianos e às italianas para pensarem a respeito da diversidade e diferença -, mas tão somente nos inspirarmos para a criação de nossa política e pedagogia de educação infantil à brasileira, macunaímica!

Lembremos que o poeta Mário de Andrade, quando, em 1924, escreveu a obra-prima da literatura brasileira, Macunaima, já nos alertava para a importância e especificidade das nossas diferenças: o herói sem nenhum caráter nada mais é do que a mistura de todos os caráteres (brancos, negros, indígenas). (FARIA, 2003, p. 69)

As pedagogias da infância só podem estabelecer seus desafios a partir dos contextos políticos, econômicos, culturais e sociais em que as crianças estão imersas; por isso, não há narrativa, abordagem, método ou característica que consiga elaborar um estatuto de uma pedagogia descolonizadora. Fatores esses que a tornam macunaímica, afinal, "sem nenhum” é equivalente a "com todos" (SANTOS; SANTIAGO; MACEDO; BARREIRO; FARIA, 2018). Pensar esses questionamentos, quando há uma educação que racializa desde a pequeníssima infância, seja pela não valorização da 
diversidade cultural e dos aportes ancestrais que destoam dos elencados pelos europeus como corretos e verdadeiros, seja pela violência hierárquica que justifica a divisão social do trabalho e a estrutura de classe, não pode ser um questionamento somente de alguns grupos sociais. A educação das crianças é uma responsabilidade de toda a sociedade e sem esse movimento não poderemos ver a construçáo da democracia ou a igualdade de direito entre todos e todas.

\section{A participaçáo infantil no campo da interculturalidade: desafios do cenário brasileiro}

No Brasil, a Pedagogia da Infância de abordagem 'macunaímica', descolonizadora, que contemple as diferenças para além da constatação da multiculturalidade, pode ser analisada por meio de diversas nuances. Se concentrarmos a análise nos processos educativos decorrentes da Constituinte de 1988, temos o reconhecimento da criança pequena como sujeito histórico e de direitos, cuja educação compete não apenas à família, mas também ao Estado, no âmbito do direito à creche e pré-escola, com projeto político-pedagógico estruturado e referenciado. Do mesmo modo, reconhece-se a diversidade cultural e étnico-racial brasileira e a igualdade de direitos a todo cidadão e a toda cidadá, indistintamente.

Considerando o movimento de defesa de creches públicas com infraestrutura e recursos humanos adequados para a garantia de educaçáo de qualidade para as crianças brasileiras desde o nascimento, há nele também uma demanda pela abordagem das diferenças visando à superação das desigualdades raciais com conhecimento, reconhecimento e valorização da cultura e história da populaçáo negra, e combate à desigualdade racial. Essa demanda surge dos próprios negros, organizados enquanto movimentos sociais, num processo de denúncia e reivindicação por uma educação que aborde a trajetória histórica de luta e participação na construção do país, de modo que meninas negras e meninos negros possam ter orgulho de seu pertencimento racial. No âmbito da creche e da pré-escola está em jogo a compreensão do cotidiano que envolve crianças, famílias e profissionais de diferentes origens étnico-raciais, sociais e culturais, de tal modo que urge superar propostas pedagógicas centradas no adulto, numa pedagogia 
colonizadora, 'brancocêntrica' e cristã. Considera-se que nesses espaços encontra-se uma pluralidade de histórias, trajetórias, vivências, crenças, conhecimentos que traduz a importância de organizaçáo do tempo-espaço pedagógico e de propostas educativas que se valham da escuta e da observação das crianças visando ao diálogo e conhecimento interculturais.

A perspectiva intercultural brasileira envolve um processo diferente do multiculturalismo, pois este acaba por corroborar as diferenças - ou a multiculturalidade - com políticas públicas que não superam de fato a desigualdade em termos sociais e raciais. A interculturalidade é um processo mais amplo de convivência entre diferentes, uma perspectiva que ultrapassa o estabelecimento de "um lugar próprio, um lugar seu diferente do de outro sujeito, ou seja, cada sujeito social ou grupo tem assim, mediante a diferente reconhecida, um lugar próprio demarcado hierarquicamente." (GUSMÃO, 2017, p. 80) Contudo, como mencionado, a produção de subjetividades em torno da criança negra e do grupo que representa caracteriza-se pela negação e distorção históricas em favor de uma perspectiva unívoca e monocultural eurocêntrica. Assim, diante de um contexto multicultural, de diferenças sociais, culturais e étnico-raciais, a educação, que deveria envolver a todos e reconhecer uma pedagogia macunaímica, tem produzido hierarquização de conhecimentos e identidades.

A supremacia de perspectivas culturais e saberes erigidos pelo colonizador relegam, historicamente, às culturas de origem africana e indígena um segundo plano, caracterizado pelo silêncio e pela estigmatização. Aqui, não a raça biológica, mas o conceito que nos revela como são agenciados e representados socialmente, no bojo das relaçôes sociais e em âmbito institucional, os corpos, a cultura e modos de agir e ver. A estigmatização racial que subjaz ao preconceito em relação aos negros, às crianças negras, gerando discriminação e exclusão (GOMES, 2008). No contexto educacional, esse processo revela a existência de um 'não lugar' no qual são alocados os diferentes, sua trajetória histórica e cultural, seus saberes, formas de organização social e inserção na sociedade, que desafiam a educaçáo colonizadora.

Diante dessa realidade histórica, o movimento negro brasileiro, em suas muitas expressôes (GONÇALVES; SILVA, 2000), tem exigido que o Estado se ocupe de criar açóes afirmativas de valorizaçáo da identidade negra em prol de uma educaçáo democrática e do combate ao racismo. 
Uma educação que ultrapasse o multiculturalismo das datas comemorativas descoladas do projeto pedagógico e da cotidianidade, ou de abordagens à parte dos saberes e conhecimentos em construção, e encaminhe a abordagem da interculturalidade e da igualdade. Uma igualdade que supere o estereótipo, o preconceito, a discriminação, o racismo, e implique o encontro, o diálogo, a alteridade.

Uma proposta que encaminha à educação intercultural na Educação Infantil está expressa na Lei de Diretrizes e Bases da Educaçáo Nacional Brasileira, com a alteração produzida pelo artigo 26 A (Lei 10.639/03) e orientada pelas Diretrizes Curriculares Nacionais para a Educação das Relaçóes Étnico-Raciais, História e Cultura Afro-Brasileira e Africana. Trata-se de uma legislação fruto da trajetória de lutas do movimento negro por reconhecimento e valorizaçáo de sua história e cultura no país, que desafia as escolas a abordarem temáticas que superem a monoculturalidade e o eurocentrismo. As exigências dessa política educacional demanda às escolas a abertura de seu projeto pedagógico para conhecimentos e práticas que indaguem a educação colonizadora, as narrativas e interpretaçóes acerca dos fatos históricos, fazendo emergir outros atores e processos de resistência. E, nesse sentido, não se trata de mudança de foco, de uma perspectiva eurocentrada para outra africana, mas de ampliar o foco dos conhecimentos e saberes escolares que se tornaram tradicionais. Essa legislação envolve o reconhecimento das diferenças numa perspectiva integrada ao cotidiano escolar, e não fora dele ou de maneira tangenciada. Implica construir um projeto pedagógico com todas as crianças, considerando aspectos importantes para a formação do país, como a abordagem étnico-racial e afro-brasileira, buscando ampliar os conhecimentos e representaçóes infantis a respeito de pessoas e grupos, histórias e dinâmicas sociais.

Mas, no campo da interculturalidade e de sua expressão enquanto ação política, há seus riscos e desafios. No contexto brasileiro, experiencia-se a emergência das identidades de maneira cada vez mais expressiva: quando falamos de infâncias plurais, contestamos a abordagem nuclear das famílias; quando questionamos o lugar em que se alocam as mulheres, as crianças, a população negra e indígena, compreendemos a urgência de desconstruir lugares pré-definidos. Paralelamente, as demandas identitárias de grupos alcançam, a exemplo da educação para as relaçóes étnicoraciais, o âmbito do Estado e das políticas sociais. 
Essa mobilização de grupos por respeito e reconhecimento identitário envolve, no campo educacional, a definição de políticas que revelam propostas diferenciadas para o sistema escolar. E, nesse processo, indagamos os sentidos da educação diferenciada, indagamos se toda educação implica o encontro entre diferentes e a compreensão dos contextos históricos e sociais nos quais os sujeitos estão inseridos para, então, encaminhar práticas educacionais. Afinal, em que termos a educação das relaçôes étnico-raciais e a abordagem da história e cultura negra e africana nas escolas implicam uma educação 'diferente' sob moldes interculturais?

Nesse ponto, educação da infância italiana e educação infantil brasileira se encontram, visto que ambas enfrentam os desafios de superação de práticas pedagógicas que isolam sujeitos, grupos e conhecimentos a momentos e lugares específicos, diferenciados, expressando distorçóes reveladoras de cotidianos de exclusão e silenciamento. Assim, se no contexto italiano as crianças filhas de imigrantes ou imigrantes são reconhecidas e sublocadas na sociedade, de tal forma que sua cultura e trajetória social sejam deixadas à parte, no Brasil a multiculturalidade é fato inconteste, mas o que é feito a partir e com ela se traduz em práticas monoculturais que atestam a discriminaçáo e o racismo, que buscam ser superados por datas comemorativas como o 13 de Maio ou o 20 de Novembro, ocasiáo em que um currículo fechado a datas e prazos conduz professoras e professores a abordarem escravidão, a organizarem apresentaçóes de danças e jogos afro-brasileiros, sem quaisquer relação com o conhecimento e a história, sem problematização das formas de discriminação dos negros e suas lutas de resistência.

Em pesquisa realizada numa comunidade remanescente de quilombo, onde residem cerca de duzentas pessoas, parentes e descendentes de escravizados da região de Itatiba (estado de São Paulo), Souza (2015b) observou como vinte e cinco crianças produziam cultura e significados acerca de si mesmas e do grupo. Ao longo de um ano, observou que as crianças mantinham uma relação identitária, de pertencimento e de valorização da história do Quilombo Brotas, caracterizada por afirmação e orgulho, já que descendiam de uma trajetória de luta dos antepassados, que ali chegaram e permaneceram com o objetivo de conquistar a liberdade e a autonomia em relação a uma sociedade calcada na exclusão, no racismo e na discriminação aos negros. 
Por outro lado, as mesmas crianças que definiam o Quilombo como um território de liberdade, segurança, ludicidade e história a ser valorizada, opuseram-se a uma proposta dos adultos (pais e máes, tios e tias) de apresentarem uma dança (jongo) para a escola na qual estudavam. Essa dança, de origem afro-brasileira e muito brincada pelas crianças, seria uma forma de apresentar o Quilombo para a escola, durante um momento de visita no território. Diante da recusa das crianças e do silêncio que mantinham quando Souza (2015b) procurava entender, a partir delas, as relaçóes raciais na escola, a pesquisadora instigou a compreensão mais profunda dos processos decorrentes da existência de uma abordagem multiculturalista da educação escolar acerca da história da população negra. Nessa busca, compreendeu que a ação da escola, ao visitar o Quilombo, nada mais era do que uma proposta pontual de abordagem da temática étnico-racial, justamente na semana do 20 de Novembro, Dia da Consciência Negra. Essa proposta educacional de visitação ao Quilombo reverberava a perspectiva pontual e superficial das relaçôes étnico-raciais e da abordagem da história e cultura afro-brasileira e africana, relegadas a datas comemorativas, e náo a uma perspectiva de integraçáo ao currículo da escola ao longo do ano, de maneira intercultural.

Souza (2015b) concluiu que as crianças, sujeitos sociais e culturais atentos aos processos sociais que as envolvem, demonstraram, por meio da recusa, a percepçáo de que a proposta da escola acarretaria maiores distorçôes a respeito do Quilombo. Dialogando com elas, analisando suas produçóes e interaçóes, a pesquisadora entendeu que havia muito mais do que uma simples recusa ou vergonha de apresentar-se ao outro, que até aquele momento não estava disposto a conhecer a sua história fortemente ligada à cultura e história afro-brasileira e africana. Afinal, o que significa uma dança afro-brasileira senão a expressão de uma ancestralidade negada na sociedade brasileira, representada por meio de estigmas negativos criados para dizer que África e suas manifestaçôes no âmbito cultural e religioso são arcaicas, selvagens, demoníacas?

As crianças negras não quiseram se expor, preferiram a recusa ao enfrentamento direto com uma escola que as nega diariamente, ensinando à escola que conhecer é mais do que ver uma dança ou circular num território quilombola. Conhecer envolve tempo, pesquisa, superação de preconceitos, abertura ao diálogo, colocar-se no lugar do outro, trocas, alteridades - uma educação para a interculturalidade. 


\section{Consideraçóes finais}

Observamos que tanto no contexto brasileiro quanto no italiano, as diferenças culturais estão presentes de maneiras distintas, mas ambas revelam a importância de transpor fronteiras para pensar estratégias de superação da exclusão (seja do imigrante, seja da população negra) que enfrentem as desigualdades étnico-raciais e fortaleçam perspectivas coloniais.

As creches se caracterizam, de modo fundamental e fundante, como espaço de confronto e acolhimento das diferenças, o que torna importante pensar os diferentes arranjos culturais presentes em nossa sociedade. $\mathrm{O}$ acolhimento das diferentes culturas no interior da educação infantil requer estratégias que propiciem uma conexão entre as creches e as experiências anteriores vivenciadas pelas crianças; e para isso é imprescindível uma abertura nas formas de conceber e nomear o que está posto como único, certo e verdadeiro. As diferenças étnicas e raciais entre as famílias, as crianças e os/as profissionais que atuam nas creches propiciam a percepção da Educação Infantil como um local multicultural por excelência, mas em inúmeras vezes não intercultural.

Os dois contextos socioculturais também elucidam como a manutenção das desigualdades raciais subsidiam processos de exclusão social, exploração do trabalho e desumanização dos sujeitos. Afinal, se na Itália a criança imigrante é o outro com o qual não há de fato uma educação intercultural, e se essa criança acaba sendo um cidadão cujo ordenamento jurídico a aloca em segundo plano, no Brasil, para uma cidadania diferenciada, somos todos cidadáos, juridicamente, mas o cotidiano do trabalho, da educação, dos direitos fundamentais e sociais revela a criança negra como pertencente a um grupo étnico-racial de segunda categoria. E escola não é lugar de exclusão.

\section{Notas}

1 Entre as pesquisas que dão base a este texto está a financiada pela Fundação de Apoio à Pesquisa do Estado de São Paulo (FAPESP)/CAPES, processo no 2015/02464-0, que inclui uma Bolsa Estágio de Pesquisa no Exterior (BEPE), processo n 2016/25474-3.

2 Essa designação foi inicialmente utilizada por Patrícia Dias Prado (1998), que traduziu a palavra italiana picolissimi, ou os 'muito pequenos', referindo-se às crianças na idade de 0 a 3 anos completos. O objetivo principal dessa denominação, segundo Prado (1998), resulta da 
necessidade emergente de se produzir novos conhecimentos relativos dentro das ciências sociais sobre a criança pequena brasileira, tanto mais, sobre as muito pequenas, que não conhecemos, senão pela Medicina e pela Psicologia.

3 Pertencentes a países que não fazem parte da União Europeia.

\section{Referências}

BASTIDE, Roger; FERNANDES, Florestan. Brancos e negros em São Paulo: ensaio sociológico sobre aspectos da formação, manifestaçóes atuais do preconceito de cor na sociedade paulistana. 4 ed. São Paulo: Global, 2008.

CARONIA, Leizia; BOLOGNESI, Ivana. Costruire le differenze: immagini di straneiro nei contesti educativo. In: NIGRIS, Elisabetta. Pedagogia e didattica interculturale: culture, contesti, linguaggi. San Bonico: Pearson, 2015. p. 67-99.

CAVALLEIRO, Eliane. S. Do silêncio do lar ao silêncio escolar: racismo, preconceito e discriminação na educação infantil. São Paulo: Contexto, 2003.

CESARO, Vicenzo Società multietniche e multiculturalismo. Milano: Vita e Pensiero, 2000.

CURCIO, Anna; MELLINO, Miguel. La Razza al Lavoro: Rileggere il razzismo, ripensare l'antirazzismo in Itália. In: CURCIO, Anna; MELLINO, Miguel. (orgs.) La razza al lavoro. Roma: Manifesto Libri, 2012, p. 7- 36.

DIAS. Lucimar Rosa. Diversidade Étnico-racial e Educação Infantil. Três Escolas. Uma questão. Muitas Respostas, Dissertação (Mestrado em Educação), UFMS, 1997.

. No fio do horizonte: educadoras da primeira infância e o combate ao racismo.

2007. Tese (Doutorado em Educação) - Faculdade de Educação, Universidade de São Paulo, São Paulo, 2007.

FARIA, Ana Lúcia G. O espaço físico como um dos elementos fundamentais para uma pedagogia infantil. In: FARIA, Ana Lúcia G.; PALHARES, Mariana (orgs). Educação infantil pós - LDB: rumos e desafios. Campinas: Autores Associados, 4 ed., 2003, p. $67-100$.

FERNANDES, Florestan. A integração do negro na sociedade de classes. São Paulo: Gloral, 2008.

. O negro no mundo dos brancos. 2. ed. São Paulo: Global, 2007.

FONTAINE, Anne-Marie; L'osserrvazione al nido: guide per educatori e professionisti della prima infanzia. Verona: Erickson, 2017.

GOMES, Nilma L. Sem perder a raiz: corpo e cabelo como símbolos da identidade negra. Belo Horizonte: Autêntica, 2008. 
GONÇALVES, Luiz A. O., GONÇALVES e SILVA, Petronilha B. Movimento negro e educação. Revista Brasileira de Educação, Rio de Janeiro, n. 15, set-dez, 2000, p. 134 -158 .

GUSMÃO, Neusa M. M. De. Interculturalidade e educação: diálogo e conflito na formação e prática docente. Devir Educação, Universidade Federal de Lavras, v. 1, n. 1, 2017, p. 75-96.

HANNERZ, Ulf. La diversità culturale. Bologna: Il Mulino, 2001.

HASENBALG, Carlos. Discriminação e desigualdades raciais no Brasil. Rio de Janeiro: Graal, 1979.

INFANTINO, Agnese. Cultura dell'infanzia e servizi educativi: persistenze e innovazione. In: CAGGIO, Francesco; INFANTINO, Agnese. (Orgs.) ... Con bambini e famiglie. Un'esplorazione in luoghi d'infanzia. Milano: Edizioni Junior, 2008. p. 171-199.

JEDLOWSKI, Paolo. Il sapere dell'esperienza: fra l'abitudine e il dubbio. Roma: Carocci Editore, 2008.

MELINO, Miguel. La critica postcoloniale: descolonizzazione, capitalismo e cosmopolitismo nei postcolonial studies. Roma: Meltemi, 2005.

NIGRIS, Elisabetta. Insegnare e apprendere fra le culture. Um approccio transculturale e inclusivo della didattica. In: NIGRIS, Elisabetta. Pedagogia e didattica interculturale: culture, contesti, linguaggi. San Bonico: Pearson, 2015, p.101-139.

OLIVEIRA, Fabiana. Um estudo sobre a creche: o que as práticas educativas produzem e revelam sobre a questão racial? Dissertaçáo (Mestrado em Educação) - Centro de Educação e Ciências Humanas, Universidade Federal de São Carlos (UFSCar), São Carlos, 2004, 112 fls.

PEREIRA, Artur Oriel. "VOCÊ QUER SER MEU AMIGO?”: um estudo interseccional das práticas de amizade entre as crianças pequenas na educação infantil. Relatório de Qualificação - Programa de Pós-Graduação em educação. Universidade Estatual de Campinas, Campinas, 2019.

PRADO, Patrícia. D. Educação e cultura infantil em creche: um estudo sobre as brincadeiras de crianças pequenininhas em um CEMEI de Campinas/SP. 1998. 139 f.Dissertação (Mestrado em Educação) - Faculdade de Educação, Universidade Estadual de Campinas, São Paulo. 1998. 
QUIJANO, Anibal. Colonialidade do poder, eurocentrismo e América Latina. In: LANDER, Edgardo. (Org.) A colonialidade do saber: eurocentrismo e ciências sociais. Perspectivas latino-americanas. Colección Sur Sur, CLACSO, Ciudad Autónoma de Buenos Aires, Argentina, 2005, p. 107-130. Disponível em: https://edisciplinas. usp.br/pluginfile.php/2591382/mod_resource/content/1/colonialidade_do_saber_ eurocentrismo_ciencias_sociais.pdf. Acesso em: 08 dezembro de 2019.

ROSEMBERG, Fulvia. Educação infantil, classe, raça e gênero. Cadernos de Pesquisa (Fundação Carlos Chagas), São Paulo, v. 96, 1996, p. 3-86.

SANTIAGO, Flávio. Estudos pós-coloniais e o emprego da categoria racial nas pesquisas europeias: uma entrevista com Miguel Mellino. ETD - Educação Temática Digital, Biblioteca da Faculdade de Educação, Unicamp. Campinas, SP, v. 20, n. 2, p. 570-578, abr. 2018. ISSN 1676-2592. Disponível em: <https://periodicos.sbu.unicamp. br/ojs/index.php/etd/article/view/8651375>. Acesso em: 26 mar. 2019. doi:https:/doi. org/10.20396/etd.v20i2.8651375.

SANTOS, Solange Estanislau dos; SANTIAGO, Flávio; MACEDO, Elina Elias de; BARREIRO, Alex; FARIA, Ana Lúcia Goulart de. Apresentação: discursos e políticas de resistências para se pensar pedagogias descolonizadoras. In: SANTOS, Solange Estanislau dos; SANTIAGO, Flávio; MACEDO, Elina Elias de; BARREIRO, Alex; FARIA, Ana Lúcia Goulart de. (orgs.) Pedagogias descolonizadoras e infâncias: por uma educação emancipatória desde o nascimento. Maceió: Edufal/ Imprensa Oficial Graciliano Ramos, 2018, p. 13-26.

SANTIAGO, Flávio. "O meu cabelo é assim... igualzinho o da bruxa, todo armado". Hierarquização e racialização das crianças pequenininhas negras na educação infantil. Dissertação (Mestrado em Educação) - Faculdade de Educação, Unicamp. Campinas/ SP, 2014, 147f.

Eu quero ser o Sol: (Re)interpretaçôes das interseç̧óes entre as relaçóes raciais e de gênero nas culturas infantis entre as crianças de $0-3$ anos em creche. Tese (Doutorado em Educação) - - Faculdade de Educação, Unicamp. Campinas/SP, 2019. 112 f.

SILVA, Clara. Intercultura e cura educativa nel nido e nella scuola dell'infanzia. Parma: Edizioni Junior, 2011. . Entrevista concedida a Flávio Santiago. 17 maio 2018, UniFI: Firenze.

SILVA, Consuelo. D. Negro, qualé o seu nome? Belo Horizonte: Mazza, 1995.

SIRNA, Concetta. Postcolonial education e societá multiculturali. Lecce: Pensa Multimedia, 2003.

SOUZA, Ellen Gonzaga de Lima. Percepçôes de infância de crianças negras por professoras de Educação Infantil. Dissertação (Mestrado em Educação) - Universidade Federal de São Carlos, 2012a. 
SOUZA, Marcia Lúcia Anacleto de. Ser quilombola: identidade, território e educação na cultura infantil. Tese de Doutoramento. Campinas, SP, UNICAMP, 2015 b.

TRINIDAD, Cristiane. Identificação étnico-racial na voz de crianças em espaços de educação infantil. Tese (Doutorado em Psicologia). Pontifícia Universidade Católica de São Paulo, São Paulo, 2011, 222f.

TOGNETTI, Gloria. I servizi educativi per l'infanzia. Contesti di relazione tra identità e diversità. In: SILVA, Clara. Educazione e cura dell'infanzia nell'Unione Europea, Edizioni ETS: Pisa, 2016, p. 281-290.

VIGNA, Carmelo; ZAMAGNI, Stefano. Multiculturalismo e identità. Milano: Vita e Pensiero, 2004.

Recebido em 8 abr. 2019 / Aprovado em I9 dez. 2019

Para referenciar este texto:

SANTIAGO, F.; SOUZA, M. L. A.; FARIA, A. L. G. Pedagogia da infância no Brasil e na Itália: a criança em contextos interculturais marcados historicamente pelo racismo. EccoS - Revista Científica, São Paulo, n. 51, er348I, out./dez. 2019. Disponível em: https://doi.org/I0.5585/EccoS.n5I.I348I. 